\title{
Detection of Delamination in Laminate Wind Turbine Blades Using One-Dimensional Wavelet Analysis of Modal Responses
}

\author{
Lukasz Doliński (D), Marek Krawczuk, and Arkadiusz Żak \\ Department of Mechatronics and High Voltage Engineering, Faculty of Electrical and Control Engineering, \\ Gdansk University of Technology, Gdansk, Poland \\ Correspondence should be addressed to Łukasz Doliński; lukasz.dolinski@pg.edu.pl
}

Received 27 October 2017; Accepted 30 January 2018; Published 1 March 2018

Academic Editor: Rafał Burdzik

Copyright (C) 2018 Łukasz Doliński et al. This is an open access article distributed under the Creative Commons Attribution License, which permits unrestricted use, distribution, and reproduction in any medium, provided the original work is properly cited.

\begin{abstract}
This paper demonstrates the effectiveness of a nondestructive diagnostic technique used to determine the location and size of delamination in laminated coatings of wind turbine blades. This is realized based on results of numerical and experimental investigations obtained by the use of the finite element method (FEM) and laser scanning vibrometry (LSV). The proposed method is based on the one-dimensional continuous wavelet transform of vibration parameters of a wind turbine blade. The investigations were conducted for a 1:10 scaled-down blade of a $36 \mathrm{~m}$ rotor wind turbine. Glass fibres and epoxy resin were used as laminate components. For numerical studies, a simple delamination model was proposed. The results obtained by the authors were used to determine the optimal set of parameters of the continuous wavelet transform. The application of high-quality LSV for experimental measurements allowed determining the optimal conditions of measuring procedures. At the same time the capabilities and limitations, resulting from the nature of the measurement method, were identified. In order to maximize the effectiveness of the detection method, preliminary signal processing was performed. Beside base wavelets also different waveform families were tested. The results obtained by the authors showed that it is possible to identify and localize even relatively small damage.
\end{abstract}

\section{Introduction}

For every technical device, there are many various factors that can start irreversible processes changing its condition and gradually deteriorate its operating characteristics. This also applies to wind turbines, where rotor blades are particularly sensitive to different kinds of defects. Rotor blades are the most important subassembly of wind turbines, which are responsible for converting the wind kinetic energy into mechanical energy. Thanks to aerodynamic forces acting on rotor blades, it is possible to generate torque, which is necessary to drive electric generators. The efficiency of wind turbines is directly related to the effective swept area of rotor blades. The simplest way to increase the power of wind turbines is to increase the diameter of their rotors [1]. The construction of large wind turbines, as well as the optimization of aerodynamic parameters of rotor blades, requires new constructional materials of predefined mechanical properties which provide high mechanical strength at relatively low weight, when compared to metallic materials. Such materials are laminated composite materials. The main components of laminates are the matrix and the reinforcement. The matrix holds laminate components together, whereas the reinforcement provides transfer of loads. The reinforcement usually takes form of very stiff and durable fibres. Nowadays, wind turbine blades are made of glass or carbon fibre laminates, which consist of several composite layers. Individual layers can possess the same or different mechanical properties. By changing the configuration of reinforcing fibres, or laminated components materials, the optimal material features can be obtained. This makes it possible to decrease the overall mass of wind turbine blades, while maintaining or enhancing the value of permitted loads. Honeycomb composites and additional noncomposite stiffeners can be used in some designs of wind turbine blades. Their designs should also include elements of lightning protection systems [2]. As a result, very complex products are obtained. Despite many advantages of laminated composite materials, they turn out to be vulnerable to very specific damage types that are characteristic only for these types of materials. In 
most cases their damage is related to degradation of their internal structure, which is also the most dangerous type of damage and very difficult to detect. A typical example can be the loss of cohesion between individual fibres (socalled fibre splitting/debonding) or between laminate layers (delamination) [3]. There are no external symptoms visible on the surface of wind turbine blades, which would indicate damage presence. Thin-walled components are particularly vulnerable to delamination. This applies to wind turbine blades, where the cause of damage is not only due to wind or centrifugal forces, but also due to dynamic loads resulting from long-term vibrations of rotor blades around resonance frequencies. The expected lifetime of wind turbine rotor blades varies from 10 to 30 years and the number of vibrations cycles during that time span is considerable. Therefore the influence of operating fatigue on the strength reduction of wind turbine rotor blades is high. Damage can also be caused by impact (e.g., bird collisions) or by lightning. These factors are particularly important for the durability and reliability of wind turbine blades. Downtime of wind turbines caused by failure recovery is associated with significant financial costs. Disassembling and replacing damaged parts at heights of several dozen meters is always a very difficult operation. This process gets even more complicated in the case of offshore wind turbine installations. Because of that intensive work is carried out to create delamination detection, identification, and localization methods in laminated coatings of wind turbine blades. Thanks to real time condition monitoring of wind turbine blades it is possible to detect damage at its early stage of development. This also makes it possible to create favourable conditions for failure-free work in assumed time or even to prolong wind turbine blades life. Appropriately quick response can significantly minimize the influence of damage to other elements of wind turbine structures. In modern designs of wind turbines, diagnostic systems are often integral parts of rotor blade structures. Examples of such systems can be found in [4-7]. Solutions proposed there could be autonomous systems of sensors used for collecting and processing data directly from working rotor blades. Most of diagnostic techniques currently used for in-service wind turbine rotor blades requires rotor stopping for the time of assessment. A field assessment of their technical condition is usually carried out during periodical inspections and is mainly based on a subjective visual assessment of rotor blade shells. This is because diagnostic methods leading to more accurate results require complex measuring instrumentation and stable measurement conditions. An example can be ultrasonic techniques [8] or computed tomography [9] used to generate surface maps of visible material defects. The main disadvantage of these techniques is that they are time consuming. For this reason ultrasonic methods can be used at the stage of production quality control and admission of rotor blades to use. Another method of considerably greater fields of applications is the image analysis employing infrared thermal cameras to observe surface temperature of wind turbine rotor blades during fatigue tests. This method effectively indicates coating cracks as well as areas at risk of failure $[10,11]$. A large number of methods used to assess the technical condition of wind turbine blades are based on classical assumptions of vibroacoustics. The popularity of these methods is due to a large amount of information transmitted by mechanical waves and their proven effectiveness in other areas of technology. One of such methods is the analysis of acoustic emission signals, which examines correlation between characteristic features of sound propagating within tested objects and their mechanical properties [1214]. Fundamental drawbacks of these methods are due to the necessity to separate useful diagnostic information from noise. In addition, as shown in [15], relatively high static loads are required to indicate damage. Basic modal parameters such as natural frequencies, mode shapes, and transmittance functions are also used. The location and size of damage can be determined by examination of differences between dynamic characteristics of undamaged and damaged states. Any detectable changes in inertia or stiffness properties of the objects under investigation and caused by damage are reflected in measured frequencies or vibration patterns that will differ from the initial undamaged state [16-20]. New methods for measuring known physical quantities (e.g., velocities or deformations), such as laser vibrometry [21] or optic fibres [22], allow for new approaches to classical vibration diagnostics, as collection of measurement data is much simpler. In addition to this improved measurement accuracy makes results more useful. The development of measurement techniques also requires the development of signal processing methods. This allows for faster, more accurate, and comprehensive data analysis. Signal processing methods include nowadays wavelet transform [23-26], fractal analysis [27], genetic algorithms [28, 29], and neural networks [30, 31].

The detection method proposed by the authors in this paper assumes measurements and analysis of vibration parameters of a scaled-down composite wind turbine rotor blade, which allows for early damage detection. A universal nature of this method also allows for its application to existing installations, regardless of their locations, the size, or type of rotor blades, as well as without the necessity for rotor stopping.

\section{Methodology}

The main objective of the investigation presented in this paper is the development of a nondestructive diagnostic method in order to determine the location and size of damage in a laminated coating of a wind turbine rotor blade. A general research methodology is schematically depicted in Figure 1. As first, modal responses of the blade are determined in terms of its natural frequencies and modes of vibrations, which next are used as the basis of the proposed diagnostic method. Also results of computer simulations and experimental measurements are presented and discussed.

Selection of useful modal parameters resulted from the requirements for the detection and localization of delamination in a relatively small area. The literature indicates that vibration frequency analysis is effective in the case of damage lengths greater than $15 \%$ of the total length of specimens $[32,33]$. In addition, it should be mentioned that natural frequencies are global parameters and thus contain 


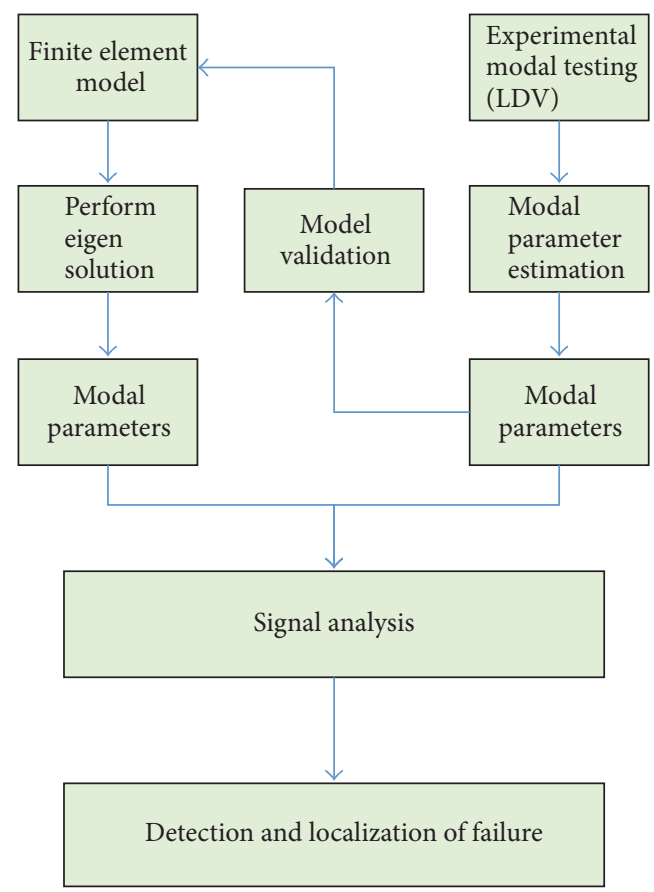

FIGURE 1: A scheme of a general research methodology.

no direct information about the location and size of damage. Therefore, it is necessary to analyse spatial domain signals searching for any discontinuities that could indicate any local stiffness changes. Modes of natural vibrations are these signal features. A continuous wavelet transform can be employed as a subsequent method of data analysis.

Figure 2 shows a more detailed concept of the presented diagnostic method. It can be seen that it assumes the application of a continuous wavelet transform (CWT) to analyse the first 10 bending modes of natural vibrations of the wind turbine blade under investigation. In order to maximize the effectiveness of the detection and localization method, preliminary signal processing was performed. Beside base wavelets also different waveform families were tested by the authors. Three different damage scenarios were taken into account, as presented in Figure 3.

2.1. Research Object. Investigations were carried out for a $1: 10$ scaled-down blade of a real wind turbine rotor, $36 \mathrm{~m}$ in diameter. The blade under investigation, $1.74 \mathrm{~m}$ in length, was based on a ClarkY aerodynamic profile. The blade was strengthened by one longitudinal spar, as shown in Figure 3. Glass fibres and epoxy resin were used as laminate components. The reinforcing fibres were symmetrically arranged as $\left[ \pm 45^{\circ}\right]_{N}$. The blade was divided into three sections, and each sections was characterized by a different number $N$ of laminate layers.

In order to avoid any sudden changes in the blade stiffness, a linear change in the coating thickness between the sections was ensured, which have a great effect of the results of wavelet analysis.

In general, the motion of wind turbine blades can be characterized by three types of vibrations: bending in the plane perpendicular to the rotor plane in the direction of the axis of rotation, bending in the rotor plane, and torsion, as shown in Figure 4. The optimal choice for spatial signal analysis presents vibrations of rotor blades perpendicular to the rotor plane.

2.2. Numerical Model. The rotor blade was modeled by the FEM. The shell finite elements used by the authors had eight nodes and six degrees of freedom at each node. The total number of finite elements of the blade numerical model was 5,409 . It was also assumed that the blade was fixed at one of its end. Numerical calculations included computations of the first 10 bending natural frequencies and modes of vibrations of the blade, with and without damage. It should be mentioned here that the current study was focused on delamination detection and localization, which is one of the most common type of damage in laminates. As a result of the forces acting on the blade during its motion, particular layers of the blade coating can be separated, leading to delamination. Figure 5 shows this damage scheme.

Characteristic features of delamination include no material loss, two possible states of damage (open and closed), and the occurrence at different depths within the laminate. This makes it difficult to develop numerical models of delamination with realistic influence on dynamic behaviour. In general, numerical models of delamination can be divided according to the research purpose. Models based on specific criteria, such as Hashin's failure criteria [34] or critical energy release rates [35], can be used to determine where and when delamination occurs, as well as how it propagates $[36,37]$. The second group of numerical models focuses on the impact of delamination on the dynamic behaviour of the objects under investigation. The simplest method of delamination modelling is the reduction of stiffness at the delamination position based on certain local changes in the thickness of laminates or based on the reduction of their Young modulus [38]. This approach gives no satisfactory results and is much better suited for crack modelling. In contrast to delamination cracks presents changes in the cross-sectional area of laminates. Other, more advanced analytical delamination models can be found in the literature [39-41]. Most of them can be assigned to one of two groups. The first group is region approaches, where laminates are divided into three distinct segments: delamination itself and two adjacent undamaged segments on both sides. The second group is layer-wise models, where multilayer theories are used directly. The main problems with both these types of delamination modelling methods result from their complexity. Therefore, in this study, a simpler delamination model was proposed. The idea used by the authors is the reduction of the shear modulus in the lamination plane $\left(G_{X Y}\right)$, which is related to zero tangential stresses within the delamination zone. The value of the shear modulus in the case of a damaged laminate was determined by examination of natural vibrations of a simple cantilever beam. The beam natural frequencies were consistent with a reference model, when the shear modulus was lowered to $14 \%$ of its initial value $[32,42]$. This method of delamination modelling is a compromise between the exact representation of damage and the ease of implementation. 


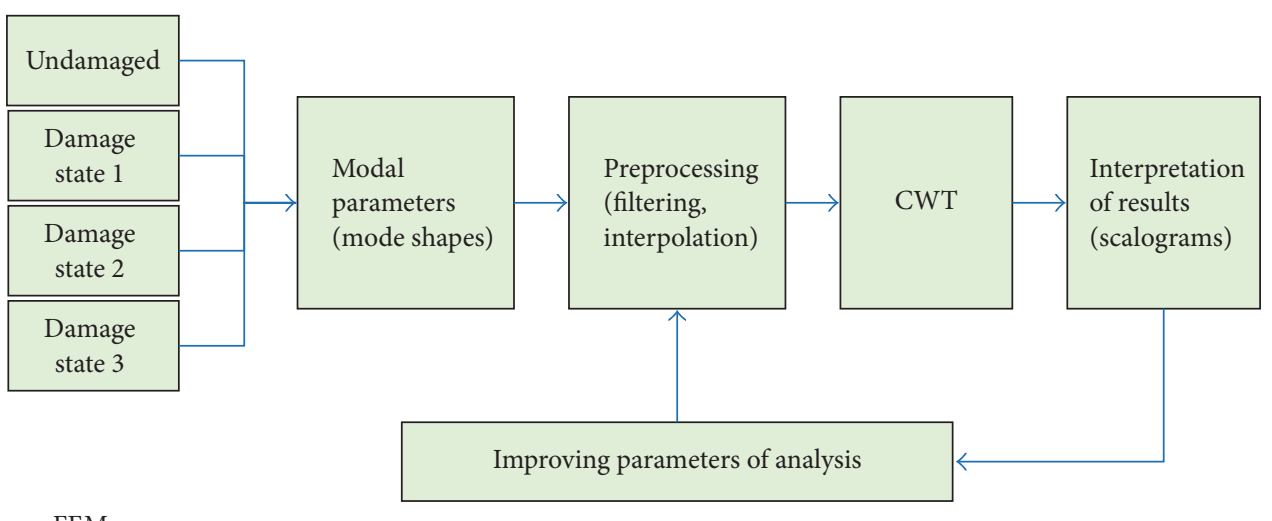

FEM

and

experiment

Research methodology

Figure 2: A scheme of detailed research methodology.

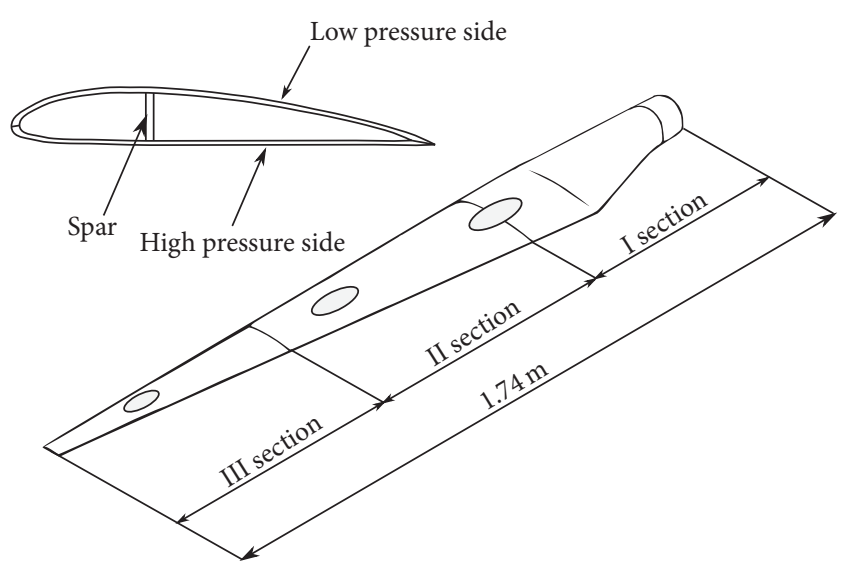

FIgURE 3: A scheme of a scaled-down wind turbine rotor blade.

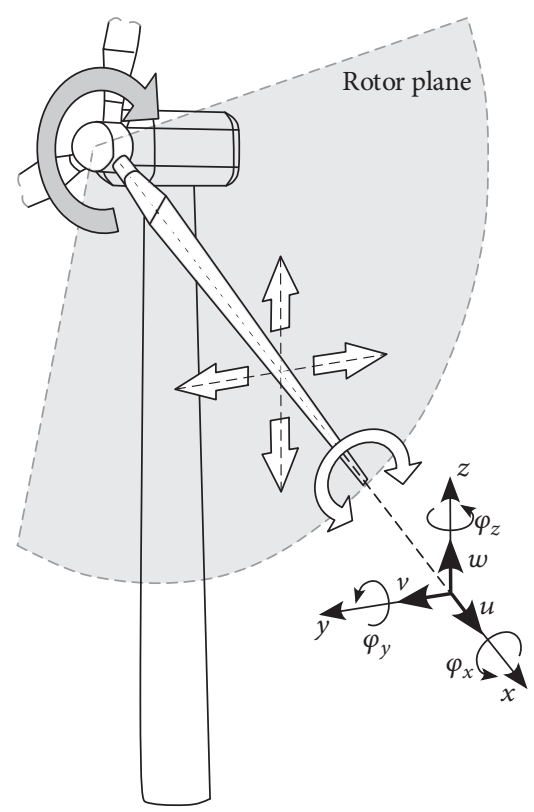

FIGURE 4: Fundamental types of vibrations of wind turbine blades.

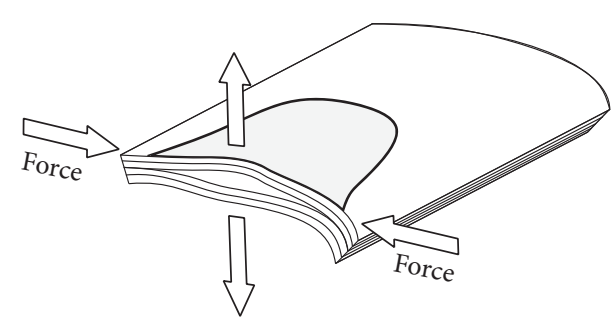

FIGURE 5: A scheme of delamination initiation.

2.3. Experimental Investigation. The main purpose of experimental measurements was validation of the numerical model of a wind turbine rotor blade proposed by the authors. Glass fibres and epoxy resin were used as laminate components. The reinforcing fibres were symmetrically arranged as $\left[ \pm 45^{\circ}\right]_{N}$. The total mass of the blade was $2 \mathrm{~kg}$. A measurement stand used by the authors is schematically presented in Figure 5 . The stand consisted the following elements: the object of investigation (1), an electromechanical shaker (7) with the maximum excitation sinusoidal force of $31 \mathrm{~N}$, and a laser vibrometer (3)-(6). The experiment was carried out using a PSV-400 Laser Scanning Vibrometer by Polytec Ltd., which enabled the authors for fast, accurate, and noncontact vibration measurements. The main and most important element of the vibrometer is a precise optical sensor (3), which is used to determine the velocities of vibrating objects. The device employs the principle of the Doppler effect to measure changes in the frequency of light reflected from vibrating objects. The vibrometer set includes a vibrometer controller, a junction box, and a control unit. The unit automatically moves a laser beam from point to point on the surface of vibrating objects over a grid of user predefined points.

The experiment conducted a series of measurements in order to determine natural frequencies and modes of vibrations of the wind turbine rotor blade under consideration at a certain initial reference state as well as three locations of simulated damage. Measurement data were collected from 200 points. A steel element fixed to the blade surface was used 


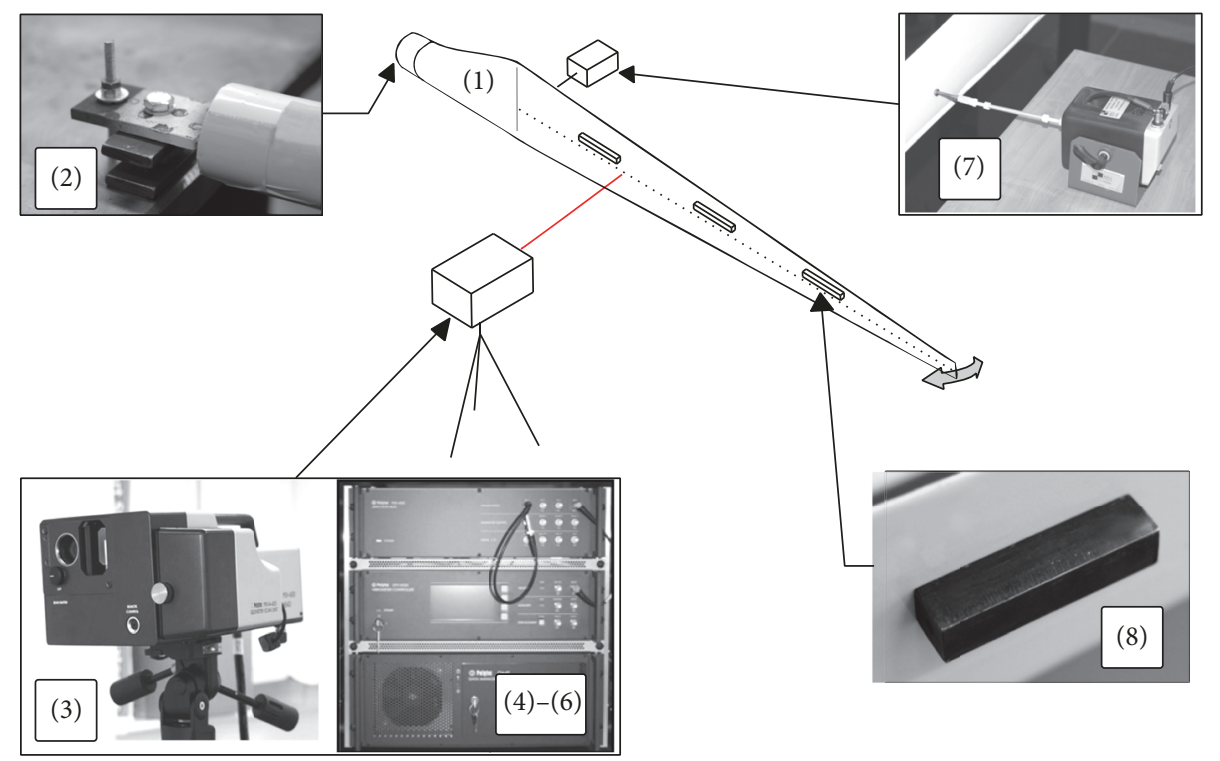

FIGURE 6: A scheme of a laboratory stand: (1) rotor blade; (2) blade fixing; (3) head of laser scanning vibrometer; (4) signal amplifier; (5) signal generator; (6) computer; (7) shaker; (8) model of damage.

to simulate damage in the form of a stiffness change in the composite coating, as shown in Figure 6.

Correct interpretation of the results of experimental data is dependent on the level of measurement noise. High noise values can mask information about the damage presence and consequently can prevent its detection. Therefore, during laboratory tests, appropriate measurement conditions were ensured, in order to maximize the signal level received by the vibrometer (the blade surface was coated by a special retroreflective foil) as well as isolate the blade from any external vibrations. The results of measurements are frequency response functions (FRFs), used to determine the values of natural frequencies and corresponding modes of induced vibrations. The induced vibrations of the blade were excited by a sinusoidal force of a constant amplitude and a linearly varying instantaneous frequency, as presented in Figure 7. Figure 8 shows a typical frequency response function obtained from all measurements points and next averaged, with peaks corresponding to resonance frequencies. Experimental measurements were conducted in the frequency range from $0 \mathrm{~Hz}$ to $550 \mathrm{~Hz}$, with a resolution of 6400 FTT lines. It should be pointed out here that the modes of induced vibrations obtained by this method do not provide sufficiently low noise levels.

For this reason, in order to minimize the noise level, a FastScan mode of measurements was used, in which each mode of vibration was determined separately based on a sinusoidal excitation at a constant frequency equal to the frequency of the measured resonant vibrations. Such measurements were carried out for a narrow frequency bandwidth of $0.02 \mathrm{~Hz}$. Figure 9 compares the results of FFT and FastScan modes for the first mode shape measured. The accuracy of data obtained is directly related to the extended measurement time. For example, the most accurate measurements of the first form of vibrations, for 200 measurement

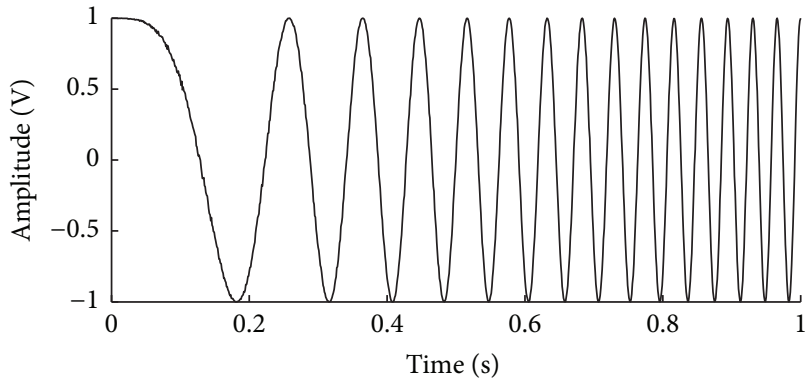

Figure 7: A typical form of an excitation signal used during experimental measurements.

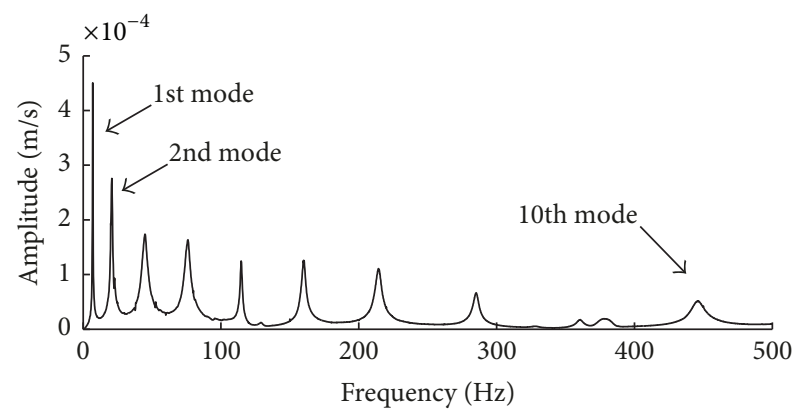

Figure 8: A typical frequency response function measured experimentally.

points, took about 3 hours. It is worth mentioning that it is impossible to provide stable excitation parameters and operating conditions in the case of a real wind turbine blade for such a long time.

Based on measured frequency response functions, presented in Figure 8, natural frequencies of the intact blade 


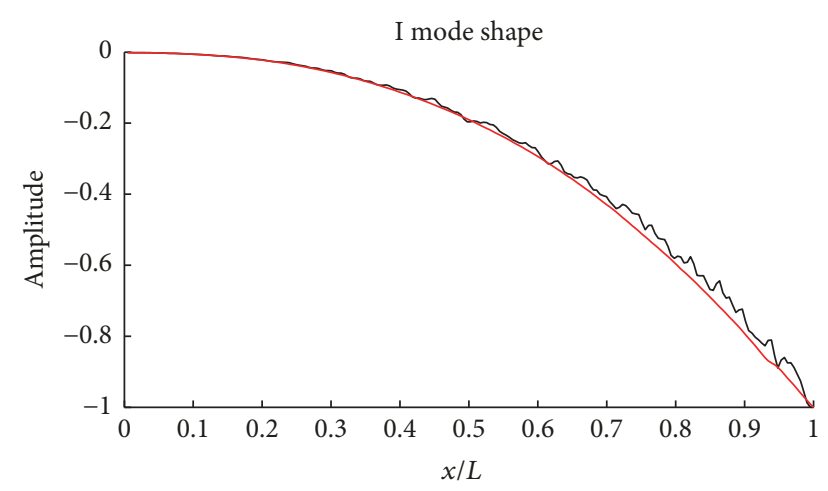

FIGURE 9: The first mode of blade natural vibrations measured experimentally: FFT (black) and FastScan (red).

were determined and compared to the values obtained from numerical simulations by the FEM. These results are shown in Table 1, where $f_{\text {Exp }}$ are the frequencies obtained experimentally and $f_{\mathrm{FEM}}$ are the frequencies obtained numerically, while appropriate differences of these frequencies are denoted as $\Delta f=\left|f_{\mathrm{Exp}}-f_{\mathrm{FEM}}\right|$.

Calculated differences for individual vibration modes up to $22.5 \%$ were primarily due to the lack of precise information about the arrangement of additional masses and local stiffeners within the blade coating. Possibly, they are all related to the bonding technology used to join the high and low pressure surfaces of the blade. However, in the case of the diagnostic method proposed in this work the source of information about the presence of damage is carried primarily by the modes of natural vibrations rather than the values of natural frequencies. Assessment of individual mode shapes, which are shown in Figure 10, allow the authors to state that the numerical model applied for FEM simulations is sufficiently precise.

2.4. Data Analysis Method. A wavelet transform was used by the authors in order to analyse the data obtained experimentally. A wavelet transform represents a process of signal decomposition into, and subsequent representation by, a linear combination of base functions called wavelets. This transformation can be seen in the context of five types of wavelets: orthogonal (Haar, Daubechies, and Symlets), biorthogonal (BiorSplines, ReversBiors), with scaling function (Meyer), without scaling function (Morlet, Mexican hat, and Gaussian), and complex (Shannon, Complex Gaussian, and Complex Morlet). Members of each family are shown in Figure 11. A full set of wave functions used in signal transformation consists of a chosen basic waveform as well as certain functions that are scaled and shifted in time by output copies. This process leads to a scalable, hierarchical representation of the signal under consideration $[43,44]$.

Wavelets are mathematical functions characterized by zero-mean, a finite signal strength, as well as a limited range and rapid decay. These characteristics determine that wavelets are well-localized both in time (or space) and frequency domains. For this reason they are particularly useful in representing signals with singular points or discontinuities.
TABLE 1: Comparison of the first 10 natural frequency values obtained experimentally and numerically.

\begin{tabular}{lcccc}
\hline Lp. & $f_{\text {Exp }}[\mathrm{Hz}]$ & $f_{\text {FEM }}[\mathrm{Hz}]$ & $\Delta f[\mathrm{~Hz}]$ & $\Delta f[\%]$ \\
\hline$(1)$ & 7,03 & 6,69 & 0,34 & 5,10 \\
$(2)$ & 20,78 & 22,48 & 1,70 & 7,56 \\
$(3)$ & 44,84 & 51,07 & 6,23 & 12,19 \\
$(4)$ & 75,94 & 91,55 & 15,61 & 17,05 \\
$(5)$ & 114,69 & 142,37 & 27,68 & 19,44 \\
$(6)$ & 159,84 & 206,18 & 46,34 & 22,47 \\
$(7)$ & 214,22 & 273,06 & 58,84 & 21,55 \\
$(8)$ & 285,16 & 350,80 & 65,64 & 18,71 \\
$(9)$ & 360,63 & 430,97 & 70,35 & 16,32 \\
$(10)$ & 445,78 & 513,01 & 67,23 & 13,10 \\
\hline
\end{tabular}

The wavelet analysis can be continuous (CWT) or discrete (DWT). In the case of DWT signal decomposition is iterative and in each iteration the original signal is decomposed into components of lower resolution. Each iteration decreases signal resolution by half. For this reason the DWT has a limited number of decomposition levels and is ineffective for low sample rates. Contrary to that the CWT makes it possible to decompose signals for any scale and allows for smooth shifting. Due to these features the CWT was used by the authors in this study. Its application leads to certain coefficients determining the similarity between a selected wavelet and the signal under investigation. These coefficients are defined by the following formula:

$$
\mathrm{CWT}_{f}(a, b)=\int_{-\infty}^{+\infty} f(t) \psi(t) d t
$$

where $a$ is a scale factor, $b$ is a shift factor, and $f(t)$ represents an analysed signal, while $\psi(t)$ denotes the fundamental wave expressed as

$$
\psi_{a b}(t)=\frac{1}{\sqrt{a}} \psi\left(\frac{t-b}{a}\right) d t ; \quad a \in R^{+}, b \in R .
$$

The scale and shift coefficients $a$ and $b$ in (2) determine the wavelength/frequency, and they change the wavelet position on the appropriate space/time axis. An important advantage of the CWT is its ability to change the transformation time resolution (frequency dependent). At low frequencies global signal information is obtained, which feature is useful for isolation of important signal characteristic. On the other hand, at high frequencies better resolution is achieved, which allows for identification of short-term characteristics obtained at the level of signal details. The results of the application of the CWT are presented in the form of scalograms in Figure 12, which graphically represent changes in wavelet coefficients at all assumed decomposition levels. High coefficient values indicate continuity of source signals.

The efficiency of the wavelet analysis is determined by the correct selection of signal preprocessing parameters and wavelet transform attributes. In the case of signals located in the spatial domain, such as are modes of natural vibrations, 


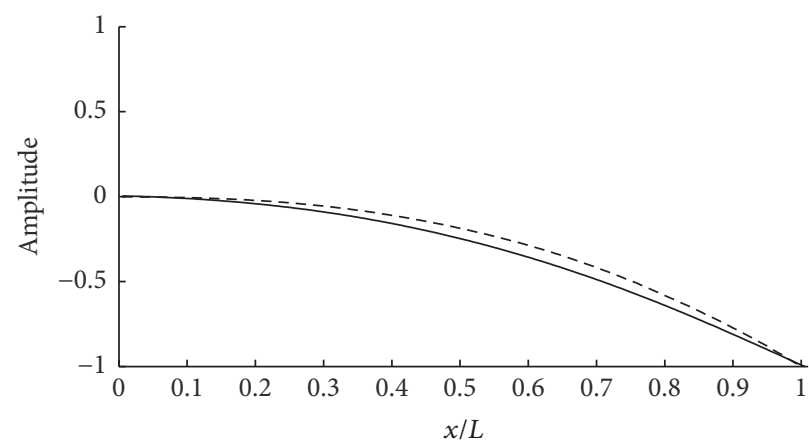

(a)

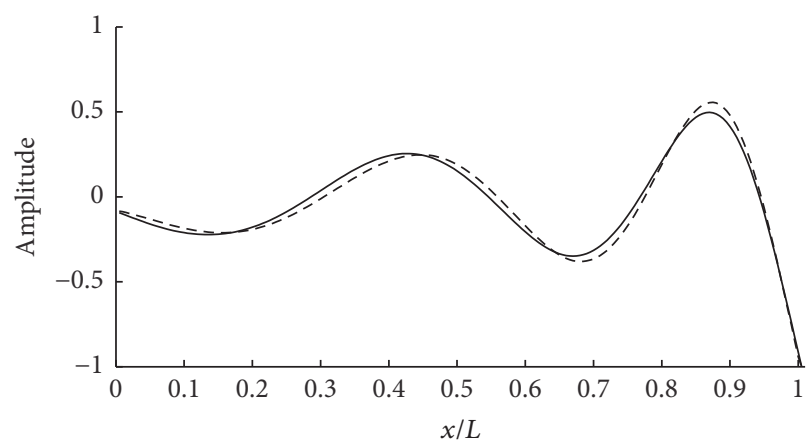

(c)

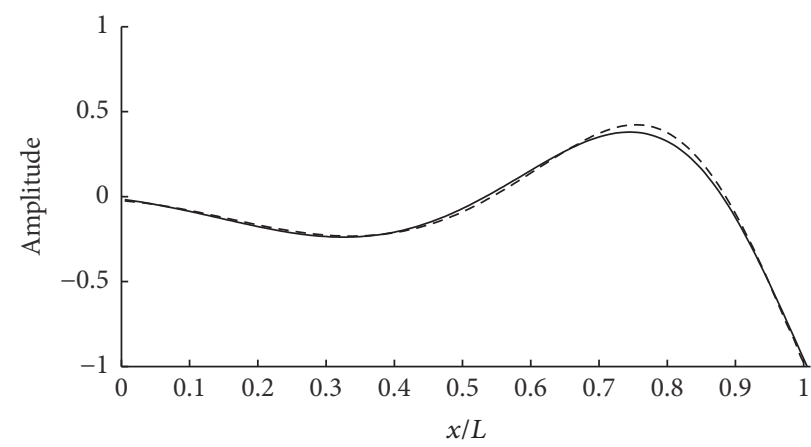

(b)

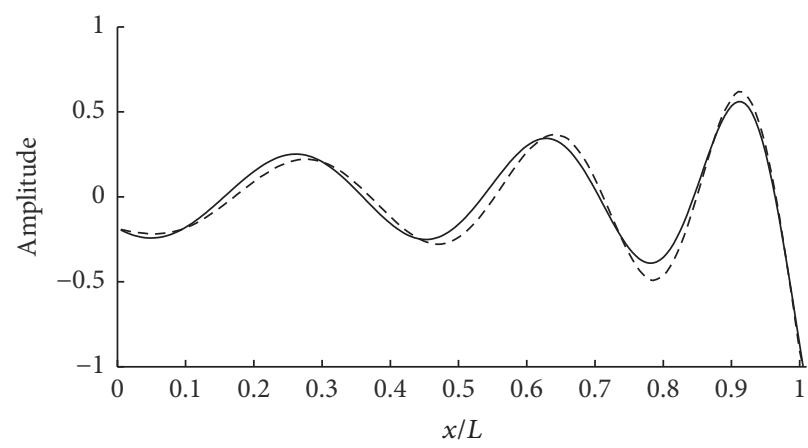

(d)

FIGURE 10: Selected modes of natural vibrations: (a) I mode, (b) III mode, (c) V mode, and (d) VII mode (experimental data: dashed line, computational data: continuous line).
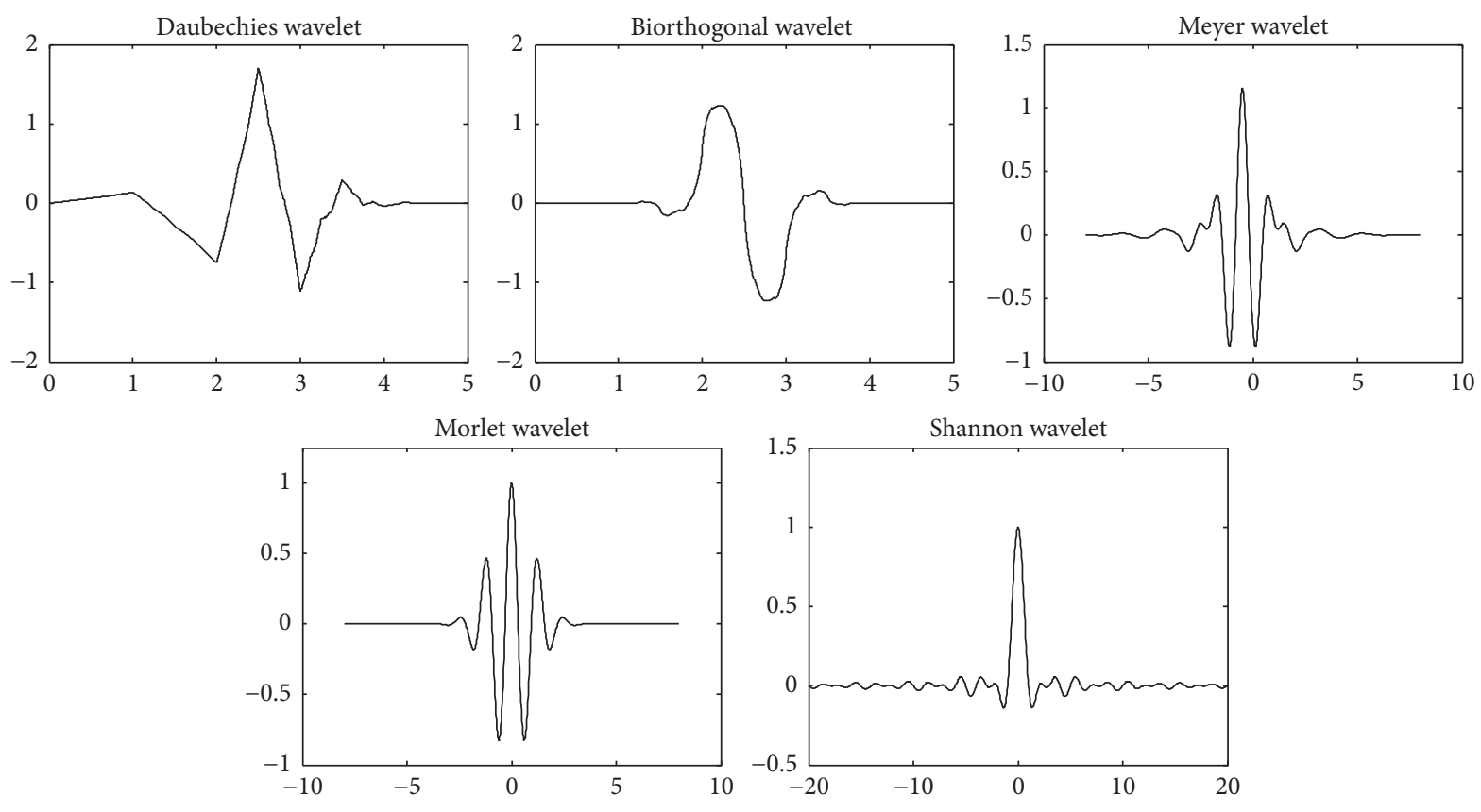

FIGURE 11: Selected examples of basic wavelet functions: Daubechies, Bior, Meyer, Morlet, and Shannon.

an even distribution of measurement points has overriding importance. It should be stated here that in the case of signals of uneven distributions of measurement points the results of wavelet analysis can be falsified. If measurements cannot be carried out for even distribution of measurement points, interpolated signals should be produced first. Interpolation is also very useful in the case of signals with small numbers of samples.

Another problem is the effect of high wavelet coefficients at the beginning and end of signals. This prevents detecting 


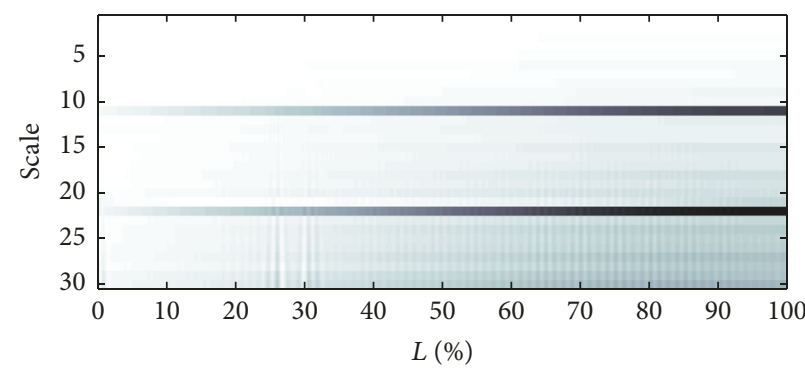

(a)

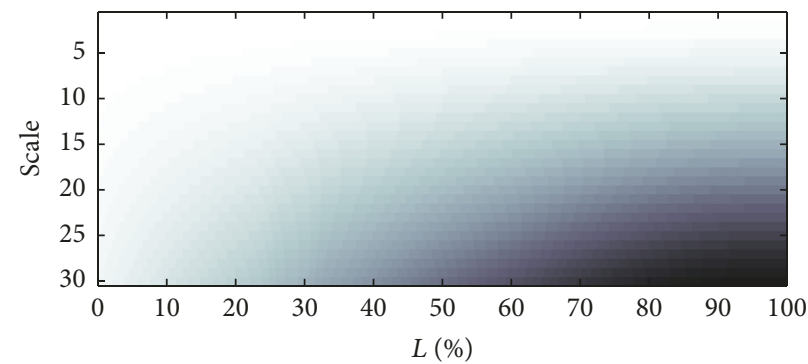

(b)

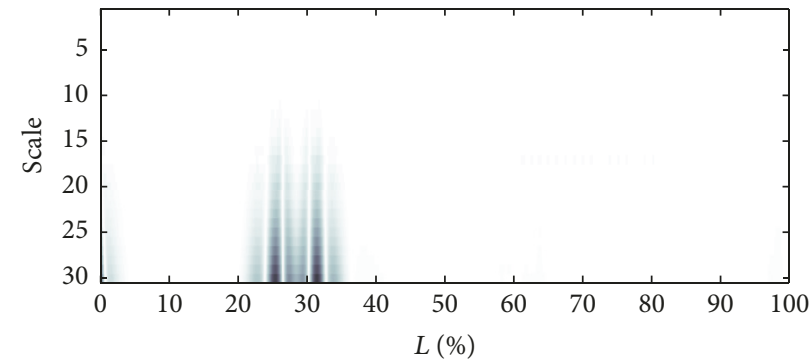

(c)

FIGURE 12: Typical scalograms obtained using different wavelet functions: (a) Morlet; (b) Haar; (c) Gauss.

and localizing damage properly. The solution to this problem is to extrapolate signals under examination at their ends, so that the zones of increased coefficient values, resulting from boundary effects, stay outside the range of interest. The type of applied interpolation and extrapolation algorithms, such as linear, polynomial, or different, depends on the form of source signals and should be chosen carefully not to introduce any additional discontinuities.

Another important aspect presents the appropriate selection of correct base wavelets. It turns out that the wavelets of orders lower than 4 generate nonzero wavelet coefficients in the entire signal lengths [45]. This feature prevents proper interpretation of calculated results. On the other hand the wavelets of large numbers of vanishing moments require high computational power and their repeated usage is time consuming. For the reasons described above in the present study base wavelets representing different families were tested in order to choose the most appropriate ones for diagnostic purposes. Figure 12 shows exemplary results of wavelet analysis obtained in the case of the blade under investigation with simulated damage located at $30 \%$ of its length, for three types of wavelets. It can be seen from Figure 12 that the most suitable base functions for the analysis of the wind turbine rotor blade is a Gauss wavelet function with four vanishing moments.

\section{Results}

Numerical results obtained by the use of the FEM model were employed to determine preprocessing parameters of signals and wavelet transform parameters such as the type of wavelet and scale. Proper interpretation of computed scalograms, in terms of damage detection, localization, and estimation its size, was obtained for

(i) linear extrapolation in order to extend the representation of selected modes of natural vibrations from initial 200 samples to 230 samples by adding 15 extra points on both signal ends,

(ii) cubic spline interpolation in order to supplement selected modes of natural vibrations with additional samples by adding 10 extra points between each two subsequent signal samples,

(iii) fourth-order Gauss base wavelet.

Scalograms for the second mode of natural vibration in the case of the intact, as well as three damage scenarios, are shown in Figures 13(a)-13(d). The simulated damage to the blade coating was successively spanning over 3,6 , and 10 measurement points.

For a majority of natural vibration modes the location of damage was identified correctly. However, for small defects of blade coating it is impossible to indicate accurately defect edges. For the 10th mode of natural vibrations detection was practically impossible, as shown in Figure 14(a).

The right side of the scalogram indicates nonzero wavelet coefficients as dark and blurry trails, that is, as the location of possible damage, whereas this part of the blade remains intact. This effect, which is noticed mainly for higher modes of natural vibrations, may obfuscate the scalogram and consequently can prevent proper damage localization. A solution to this problem is to adjust wavelets individually with higher order numbers, as seen in Figure 14(b).

Through the analysis of scalograms, in the case of one mode of natural vibrations, for all three damage locations, it 


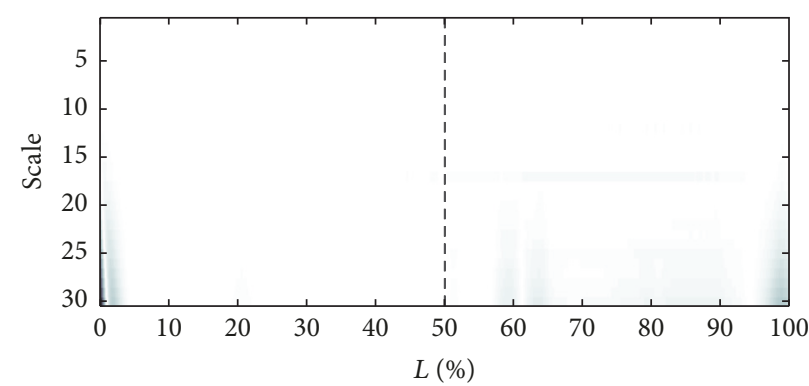

(a)

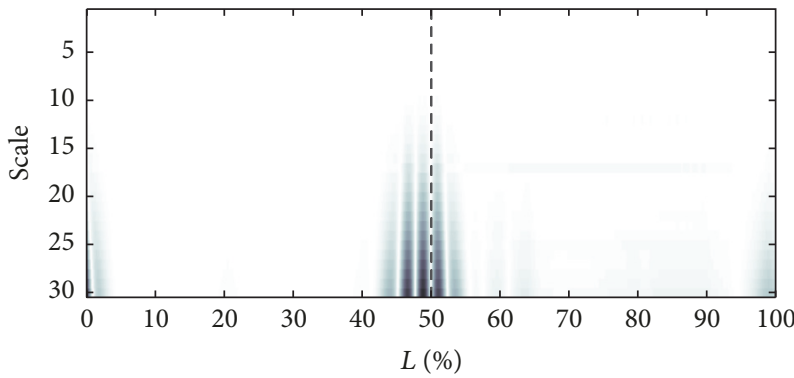

(c)

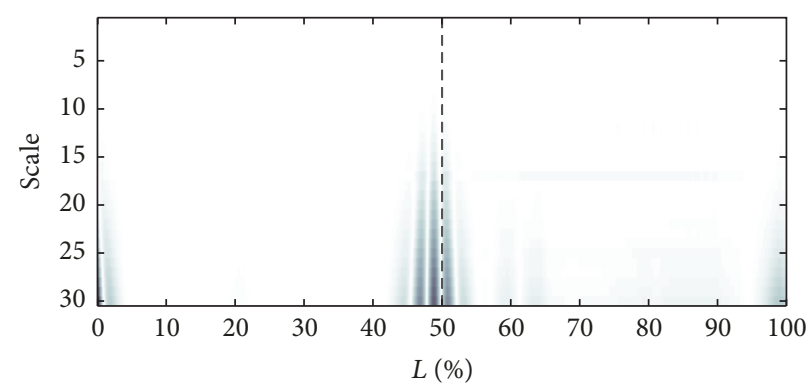

(b)

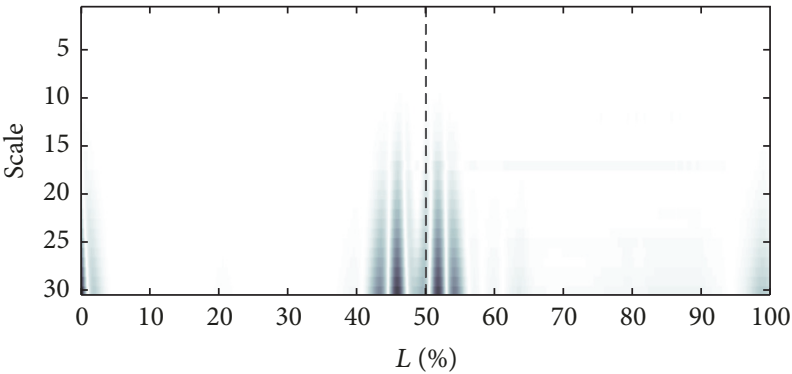

(d)

FIGURE 13: Numerical results of wavelet analysis of the 2 nd mode on natural vibrations in the case of the intact and three damage scenarios.

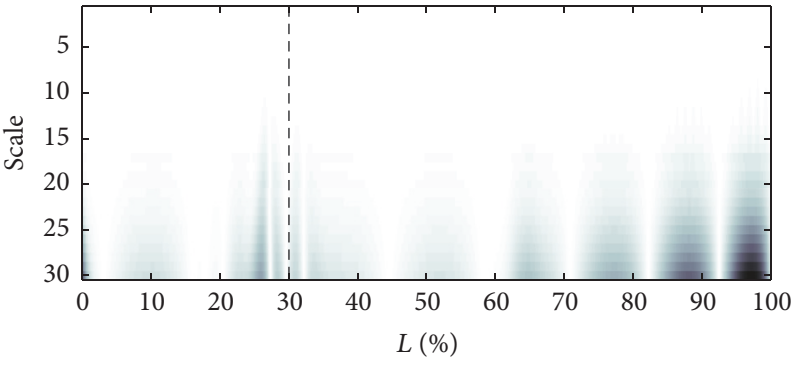

(a)

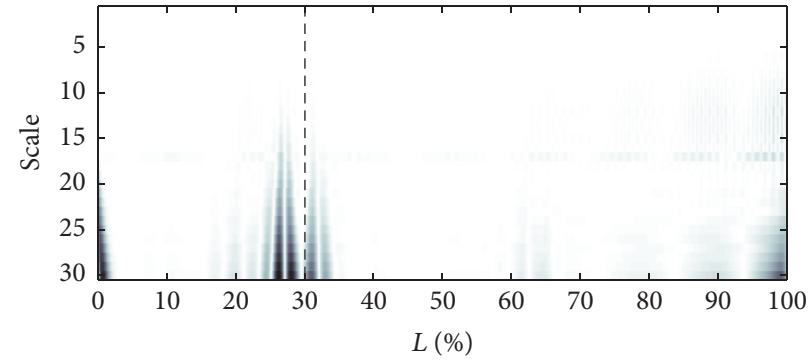

(b)

FIGURE 14: Numerical results of wavelet analysis of the 10th mode of natural vibrations in the case of Gauss4 (a) and Gauss6 (b) wavelet functions.

can be seen from Figure 15 that the visibility of damage of the same size varies according to the damage location. As shown in Figure 15(a) the effect of damage is relatively small there, where the cross-section of the blade has high stiffness values, as it is at the blade fixing. Changing the location of damage towards the tip of the blade results in an increase in the visible width of the damage zone, as presented in Figures 15(b) and 15(c). This is due to the fact that in this direction the stiffness of the blade decreases, due to a decrease in the cross-section of the blade as well as a decrease in the thickness of the blade coating.

In the first stage of the analysis of experimental signals, data processing and the analysis of CWT parameters were based on the results of numerical simulations. Figure 16 shows comparison of scalograms for the first 10 bending modes of natural vibrations obtained in the case of the blade measurements with additional stiffeners. Vertical dashed lines indicate the location of damage defining the limits of the damage zone. Based on experimental data two conclusions can be drawn as starting points in order to improve the effectiveness of the proposed damage detection method. Through the comparison of modes of natural vibrations with corresponding scalograms it is possible to correlate the location of damage with characteristic points of source signals. An increase in wavelet coefficients indicating discontinuities was observed only, if damage coincided with local signal extremes.

The second conclusion concerns the noise level observed, which is directly related to the quality of measurement signals. High noise levels make it difficult to interpret results, as local stiffness changes can result in an increase in wavelet coefficients in the same range as noise. Therefore it was 


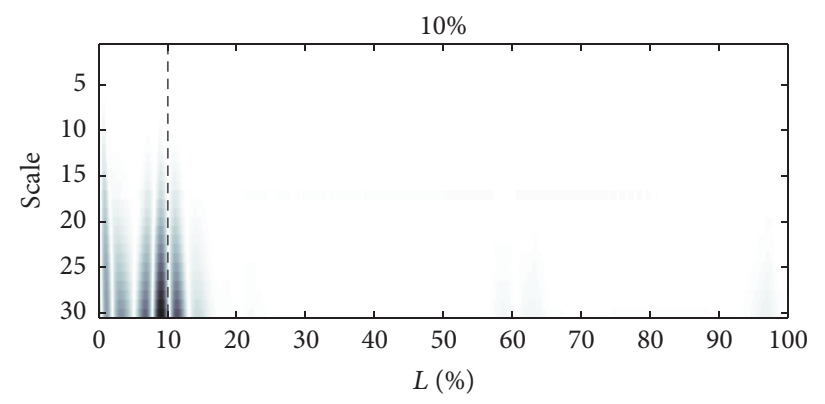

(a)

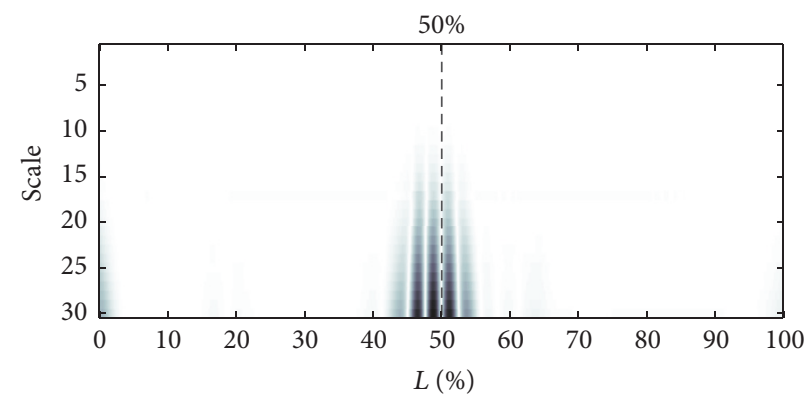

(b)

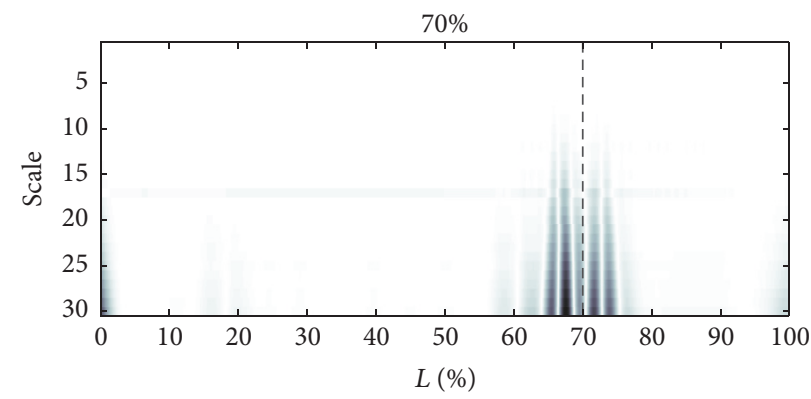

(c)

FIGURE 15: Numerical results of wavelet analysis in the case of three damage location scenarios.

necessary to modify the approach proposed by the authors to extract sharper information about the location and size of defects. It should be noticed that limited methods available to increase the accuracy of measurements make it necessary to modify signal analysis parameters.

\section{Discussion}

The main element of signal preprocessing that influences the performance of wavelet analysis is interpolation. It separates one sample of the original signal from the other by increasing signal resolution, which can be described by a one-dimensional vector. The consequence is sharpening the boundaries of any discontinuities on scalograms, which may include measurement distortions. The level of details can be reduced by reducing the number of interpolation points, thus exposing the sought after changes in a wider range, as shown in Figure 17. The effect of this is the reduction of noise visible in scalograms as well as the appearance of a clear triangular formation that indicates the damage zone.

Thanks to the approach proposed scalograms were obtained also in the case of the remaining damage location scenarios. Figure 18 shows scalogram obtained for the 8 th mode of natural vibrations in the case of damage in two extreme locations and spanning over 6 interpolation points.

It can be seen that the reduction in the number of interpolation points enabled the authors to detect damage very accurately. However, this process can cause loss of precise information about the width of the damage zone. Figure 19 shows scalograms for three different sizes of the damage zone close to the central location. Damage spanning over 12,10 , and 8 measurement points, corresponding to $6 \%$, $5 \%$, and $4 \%$ of the total measurement line, were considered.

The analysis of the experimental results shows that the key element for correct interpretation of scalograms is a low noise level as well as precise knowledge about the structure of the object under investigation. For this reason, reference signals are indispensable. Figure 20 shows the results of the CWT based on the difference between modes of natural vibrations obtained for damaged and undamaged states. In this manner the signal-to-noise ratio was improved and positive results for more cases were achieved.

Based on the results obtained for all considered cases, it can be concluded that measured signals should be analysed and assessed in a multistage manner with respect to a reference state by

(i) starting from a small number of interpolation points,

(ii) registering global changes (damage identification),

(iii) gradual increasing of the number of interpolation points, narrowing the window of determination of the damage nature and its exact boundaries.

\section{Summary and Conclusions}

The paper presents certain results of numerical simulations and calculations as well as experimental measurements aimed at developing a method for delamination detection and localization in composite wind turbine blades. Numerically and experimentally determined modes of natural vibrations of a wind turbine blade were assessed for local changes that may indicate the presence of damage. For numerical simulation a simple delamination model was proposed that allowed the 

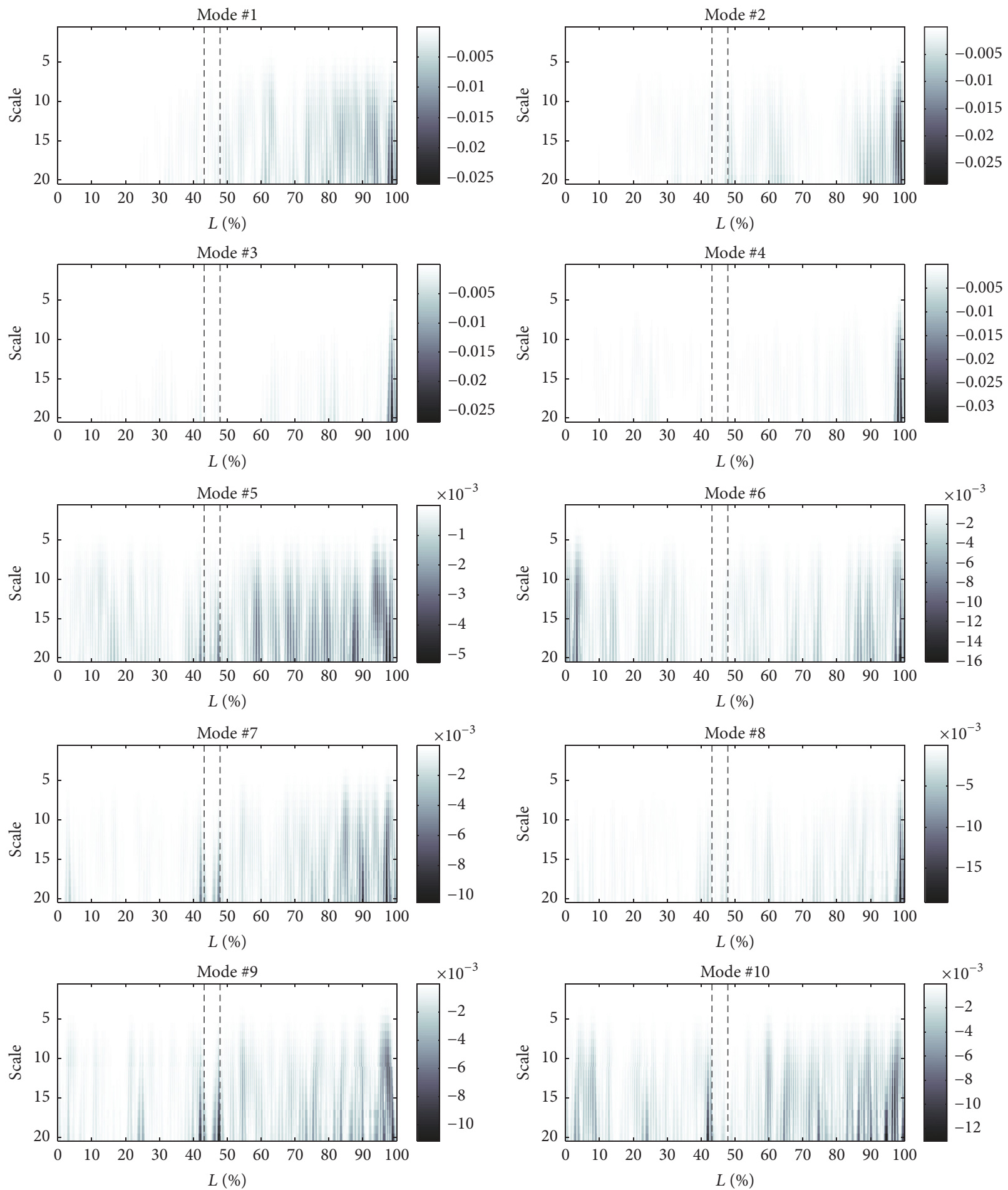

FIGURE 16: Scalograms obtained from measured data in the case of all modes of natural vibrations.

authors to calculate eight simulated damage levels in three different locations. Next the results obtained were used to determine an optimal set of parameters of the continuous wavelet transform (CWT). The second stage of the analysis included experimental research in order to verify both finite element method (FEM) based model predictions as well as the damage detection method developed. The use of highquality Scanning Laser Vibrometry allowed the authors to determine the optimal conditions and measuring procedures, which led to the required accuracy of measurement. At the same time the capabilities and limitations resulting from the nature of the measurement method were identified. 


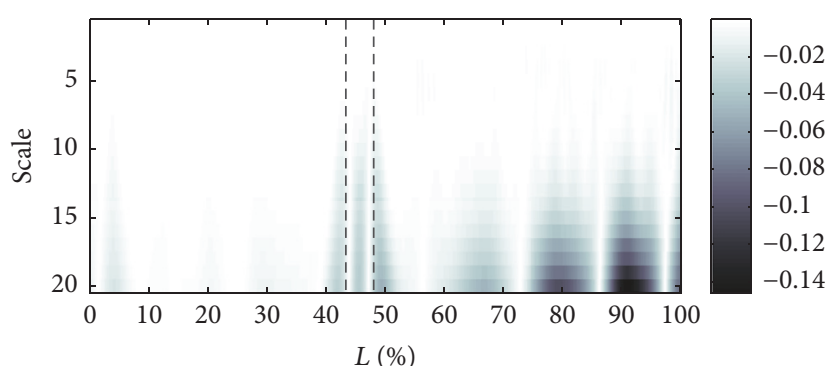

(a)

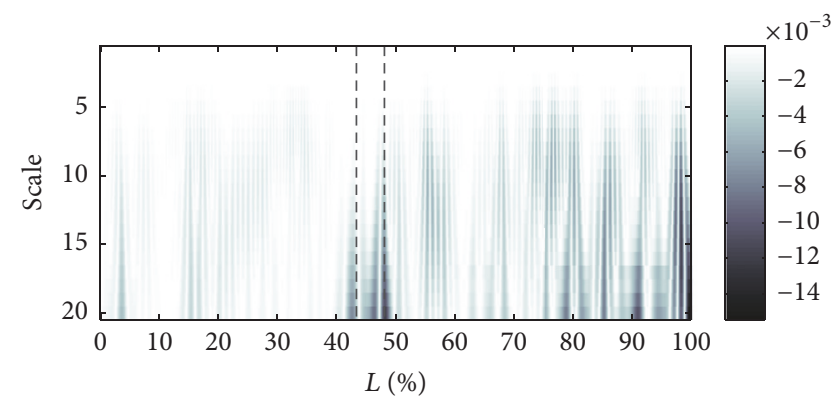

(c)

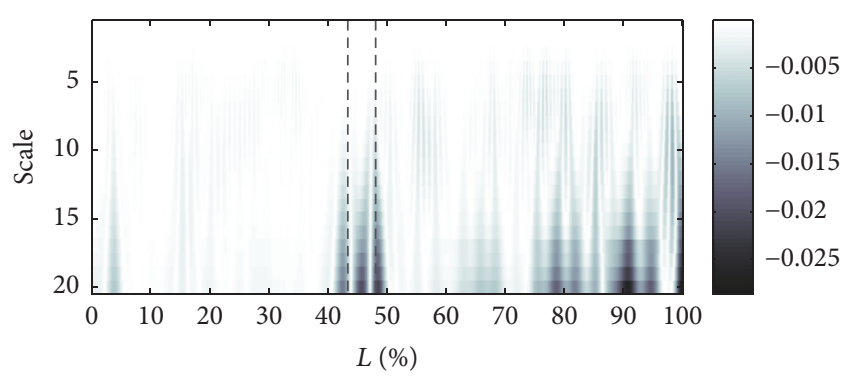

(b)

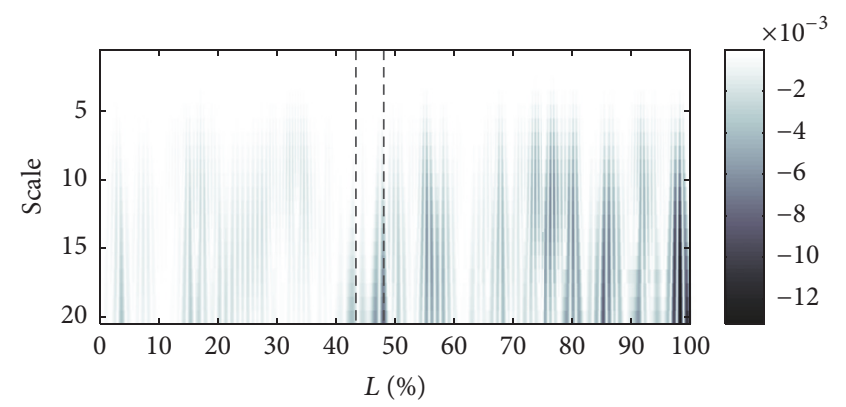

(d)

FIGURE 17: Scalograms of the 7th mode of natural vibrations in the case of different numbers of interpolation points: (a) 2; (b) 4; (c) 6; (d) 8.
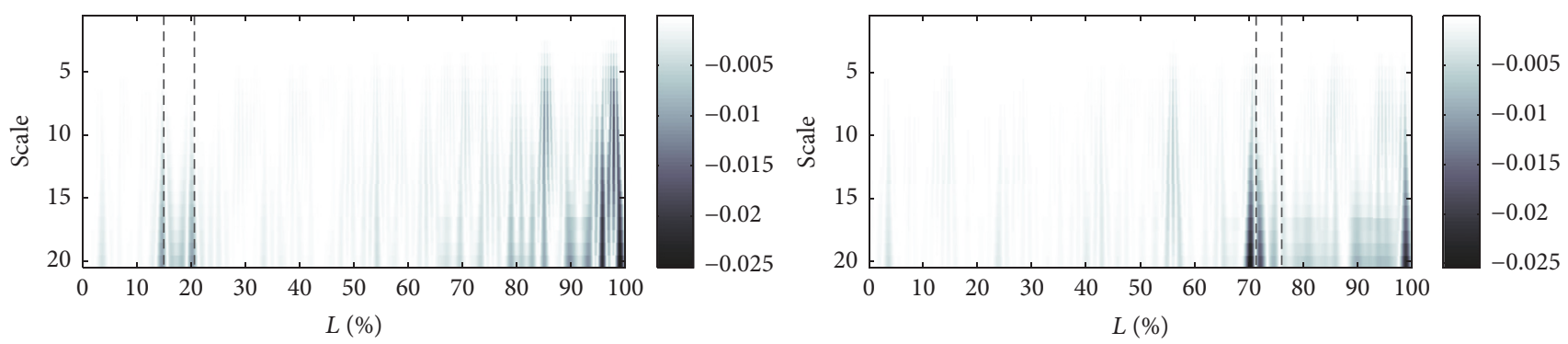

FIGURE 18: Scalograms of the 8th mode of natural vibrations obtained in the case of six interpolation points.

The main challenge in the practical implementation of a diagnostic system based on the proposed method comes from low levels of signal distortions that are sought after. The damage detection method presented can be used on an operating wind turbine based on data obtained from a system of piezoelectric or fibre optic sensors. Vibration measurements can also be performed by means of laser vibrometry supplemented by additional devices, such as is a derotator equipped with a special optical system, whose rotational motion is fully synchronized with the rotation of the object under investigation, such as are wind turbine blades.

The results of the research presented in this paper confirm the effectiveness of wavelet methods in detection of signal discontinuities. Based on them the following conclusions can be made:

(i) For best results, wavelet transform analysis should be proceeded by some signal preprocessing in the form of extrapolation and interpolation. Extrapolation reduces effects of increased values of wavelet coefficients at signal ends, while interpolation increases signal resolution.

(ii) Analysis of modes of natural vibrations and corresponding scalograms makes it possible to correlate the damage location and size with characteristic points of source signals. Only in the case when damage zones coincide with local signal extremes, it is possible to detect damage.

(iii) In the case of experimental data that are subjected to measurement noise, too many interpolation points block proper interpretation of scalograms. For this reason signals obtained experimentally should be analysed in a multistage manner, starting from a small number of interpolation points in order to observe more general changes. A gradual increase in the number of interpolation points allows determining the type of damage and its precise location. 

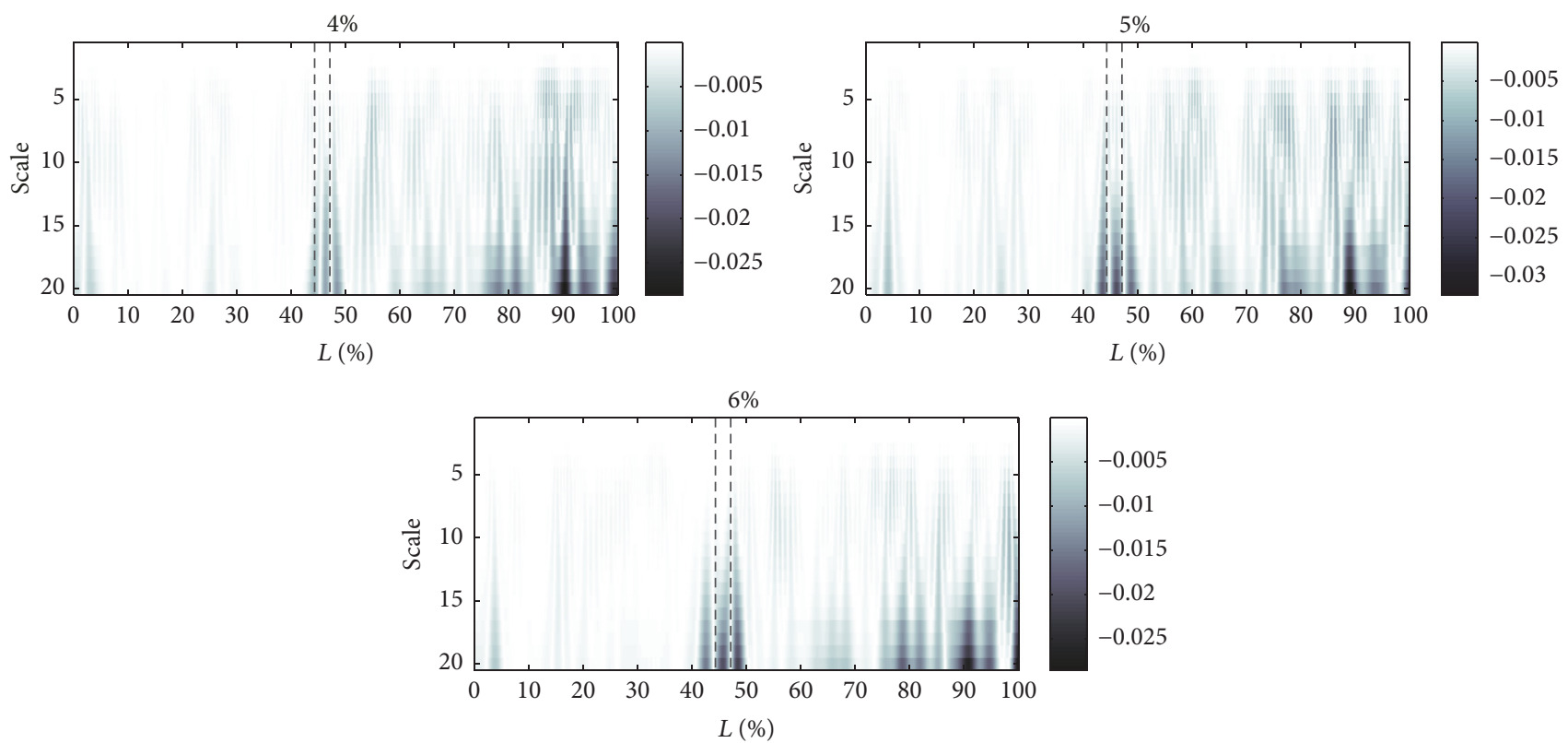

FIGURE 19: Scalograms of the 7th mode of natural vibrations obtained in the case of three different damage sizes.
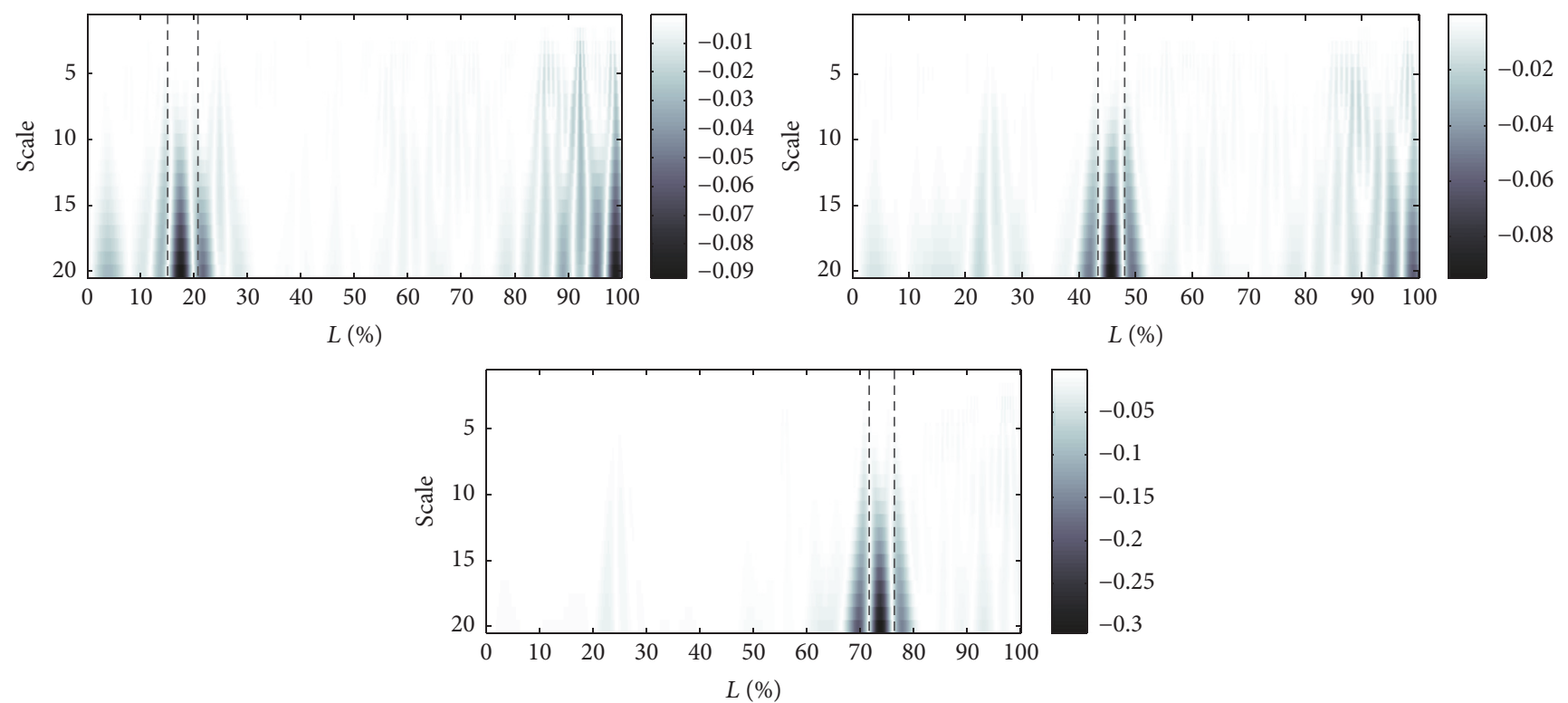

FIGURE 20: Scalograms of differential signals (damaged to reference) obtained for the 9th mode of natural vibrations for three damage locations.

(iv) Signal windowing increases the sharpness of the damage zone. This solution may be particularly important in the case of damage that has a small effect on the object dynamics.

Both experimental and numerical data indicate that the key to the correct interpretation of CWT analysis results, in the case of complex structures, is the knowledge about initial, undamaged state of the object under investigation. In the case of experiments carried out the availability of reference signals made it possible to reduce the influence of noise on the results of subsequent CWT computations.

\section{Conflicts of Interest}

The authors declare that there are no conflicts of interest regarding the publication of this paper.

\section{References}

[1] H.-J. Wagner and J. Mathur, Introduction to Wind Energy Systems - Basics, Technology and Operation, Springer, 2009.

[2] A. Ayub, W. Siew, and S. MacGregor, "External lightning protection system for wind turbine blades - further considerations," in Proceedings of the Asia-Pacific International Conference on Lightning (APL), Nagoya, Japan, 2015. 
[3] B. F. Sørensen, E. Jørgensen, C. P. Debel et al., "Improved design of large wind turbine blade of fibre composites based on studies of scale effects (Phase 1) Summary Report," 2004.

[4] G. R. Kirikera, M. J. Schulz, and M. J. Sundaresan, "Multiple damage identification on a wind turbine blade using a structural neural system," in Proceedings of the SPIE Smart Structures and Materials \& Nondestructive Evaluation and Health Monitoring, San Diego, CA, USA, 2007.

[5] M. J. Schulz and M. J. Sundaresan, "Smart sensor system for structural condition monitoring of wind turbines," Tech. Rep. NREL/SR-500-40089, National Renewable Energy Laboratory, 2006.

[6] M. J. Sundaresan, M. J. Schulz, and A. Ghoshal, "Structural health monitoring static test of a wind turbine blade," Tech. Rep. NREL/SR-500-28719, National Renewable Energy Laboratory, 2002.

[7] M. Sundaresan, M. Schulz, and A. Ghoshal, "Intelligent blade for wind turbines," in Proceedings of the 39th AIAA/ASME Aerospace Sciences Meeting and Exhibit, Wind Energy Symposium, Reno, NV, USA, 2001.

[8] J. Gieske and M. Rumsey, "Non-destructive Evaluation (NDE) Of Composite/Metal Bond Interface Of A Wind Turbine Blade Using An Acousto-ultrasonic Technique," in Proceedings of the AIAA Aerospace Sciences Meeting, pp. 249-254, 1997.

[9] A. Katunin, M. Dańczak, and P. Kostka, "Automated identification and classification of internal defects in composite structures using computed tomography and 3D wavelet analysis," Archives of Civil and Mechanical Engineering, vol. 15, no. 2, pp. 436-448, 2015.

[10] A. G. Beattie and M. Rumsey, "Non-destructive evaluation of wind turbine blades using an infrared camera," in Proceedings of the ASME Wind Energy Symposium, 18th Aerospace Sciences Meeting and Exhibit, 1999.

[11] G. M. Smith, B. R. Clayton, A. G. Dutton, and A. D. Irving, "Infra-red thermography for condition monitoring of composite wind turbine blades feasibility studies using cyclic loading tests," in Proceedings of the 15th British Wind Energy Association Conference, York, UK, 1993.

[12] J. Wei and J. McCarty, "Acoustic emission evaluation of composite wind turbine blades during fatigue testing," Wind Engineering, vol. 17, no. 6, pp. 266-274, 1993.

[13] H. Sutherland, A. Beattie, B. Hansche et al., The Application of Non-Destructive Techniques to the Testing of a Wind Turbine Blade, Sandia National Laboratories, 1993.

[14] A. G. Beattie, "Acoustic emission monitoring of a wind turbine blade during a fatigue test," in Proceedings of the AIAA Aerospace Sciences Meeting, 1997.

[15] M. J. Blanch and A. G. Dutton, "Acoustic emission monitoring of field tests of an operating wind turbine," Key Engineering Materials, vol. 245-246, pp. 475-480, 2003.

[16] J.-T. Kim, Y.-S. Ryu, H.-M. Cho, and N. Stubbs, "Damage identification in beam-type structures: frequency-based method vs mode-shape-based method," Engineering Structures, vol. 25, no. 1, pp. 57-67, 2003.

[17] L. M. Khoo, P. R. Mantena, and P. Jadhav, "Structural damage assessment using vibration modal analysis," Structural Health and Monitoring, vol. 3, no. 2, pp. 177-194, 2004.

[18] Y. Aoki and O.-I. Byon, "Damage detection of CFRP pipes and shells by using localized flexibility method," Advanced Composite Materials: The Official Journal of the Japan Society of Composite Materials, vol. 10, no. 2-3, pp. 189-198, 2001.
[19] N.-G. Park and Y.-S. Park, "Identification of damage on a substructure with measured frequency response functions," Journal of Mechanical Science and Technology, vol. 19, no. 10, pp. 1891-1901, 2005.

[20] A. Furukawa, H. Otsuka, and J. Kiyono, "Structural damage detection method using uncertain frequency response functions," Computer-Aided Civil and Infrastructure Engineering, vol. 21, no. 4, pp. 292-305, 2006.

[21] M. Radzieński, Ł. Doliński, M. Krawczuk, and M. Palacz, "Damage localisation in a stiffened plate structure using a propagating wave," Mechanical Systems and Signal Processing, vol. 39, no. 1-2, pp. 388-395, 2013.

[22] J. Sierra-Pérez, M. A. Torres-Arredondo, and A. Güemes, "Damage and nonlinearities detection in wind turbine blades based on strain field pattern recognition. FBGs, OBR and strain gauges comparison," Composite Structures, vol. 135, pp. 156-166, 2016.

[23] P. Pratumnopharat, P. S. Leung, and R. S. Court, "Wavelet transform-based stress-time history editing of horizontal axis wind turbine blades," Journal of Renewable Energy, vol. 63, pp. 558-575, 2014.

[24] A. Katunin, "Stone impact damage identification in composite plates using modal data and quincunx wavelet analysis," Archives of Civil and Mechanical Engineering, vol. 15, no. 1, pp. 251-261, 2015.

[25] A. Katunin and P. Przystałka, "Damage assessment in composite plates using fractional wavelet transform of modal shapes with optimized selection of spatial wavelets," Engineering Applications of Artificial Intelligence, vol. 30, pp. 73-85, 2014.

[26] A. Katunin, "Vibration-based spatial damage identification in honeycomb-core sandwich composite structures using wavelet analysis," Composite Structures, vol. 118, pp. 385-391, 2014.

[27] A. Banerjee and G. Pohit, "Crack investigation of rotating cantilever beam by fractal dimension analysis," in Proceedings of the 2nd International Conference on Innovations in Automation and Mechatronics Engineering, ICIAME, 2014.

[28] J.-H. Chou and J. Ghaboussi, "Genetic algorithm in structural damage detection," Computers \& Structures, vol. 79, no. 14, pp. 1335-1353, 2001.

[29] A. Raich and T. Liszkai, "Benefits of implicit redundant genetic algorithms for structural damage detection in noisy environments," in Proceedings of the Lecture Notes in Computer Science - GECCO, Berlin, Germany, 2003.

[30] C. Y. Kao and S.-L. Hung, "Detection of structural damage via free vibration responses generated by approximating artificial neural networks," Computers \& Structures, vol. 81, no. 28-29, pp. 2631-2644, 2003.

[31] Q. Chen, Y. W. Chan, and K. Worden, "Structural fault diagnosis and isolation using neural networks based on response-only data," Computers \& Structures, vol. 81, no. 22-23, pp. 2165-2172, 2003.

[32] A. Zak, M. Krawczuk, and W. Ostachowicz, "Numerical and experimental investigation of free vibration of multilayer delaminated composite beams and plates," Computational Mechanics, vol. 26, no. 3, pp. 309-315, 2000.

[33] C. N. Della and D. Shu, "Free vibration analysis of composite beams with overlapping delaminations," European Journal of Mechanics - A/Solids, vol. 24, no. 3, pp. 491-503, 2005.

[34] W. Sprenger, F. Gruttmann, and W. Wagner, "Delamination growth analysis in laminated structures with continuum-based 
3D-shell elements and a viscoplastic softening model," Computer Methods Applied Mechanics and Engineering, vol. 185, no. 2-4, pp. 123-139, 2000.

[35] O. Allix and P. Ladevèze, "Interlaminar interface modelling for the prediction of delamination," Composite Structures, vol. 22, no. 4, pp. 235-242, 1992.

[36] L. Daudeville, O. Allix, and P. Ladevèze, "Delamination analysis by damage mechanics: Some applications," Composites Part B: Engineering, vol. 5, no. 1, pp. 17-24, 1995.

[37] S. N. Wosu, D. Hui, and P. K. Dutta, "Dynamic mixed-mode I/II delamination fracture and energy release rate of unidirectional graphite/epoxy composites," Engineering Fracture Mechanics, vol. 72, no. 10, pp. 1531-1558, 2005.

[38] S. V. Kulkarni and D. Frederick, "Frequency as a Parameter in Delamination Problems-A Preliminary Investigation," Journal of Composite Materials, vol. 5, no. 1, pp. 112-117, 1971.

[39] S. Keshava Kumar, R. Ganguli, and D. Harursampath, "Partial delamination modeling in composite beams using a finite element method," Finite Elements in Analysis and Design, vol. 76, pp. 1-12, 2013.

[40] M. Marjanović and D. Vuksanović, "Layerwise solution of free vibrations and buckling of laminated composite and sandwich plates with embedded delaminations," Composite Structures, vol. 108, no. 1, pp. 9-20, 2014.

[41] D. Li and F. Zhang, "Full extended layerwise method for the simulation of laminated composite plates and shells," Computers \& Structures, vol. 187, 2017.

[42] M. Krawczuk, W. Ostachowicz, and A. Zak, "Dynamics of cracked composite material structures," Computational Mechanics, vol. 20, no. 1-2, pp. 79-83, 1997.

[43] S. G. Mallat, "Theory for multiresolution signal decomposition: the wavelet representation," IEEE Transactions on Pattern Analysis and Machine Intelligence, vol. 11, no. 7, pp. 674-693, 1989.

[44] I. Daubechies, Ten Lectures on Wavelets, Society for Industrial and Applied Mathematics, 1992.

[45] M. Rucka and K. Wilde, "Application of continuous wavelet transform in vibration based damage detection method for beams and plates," Journal of Sound and Vibration, vol. 297, no. 3-5, pp. 536-550, 2006. 


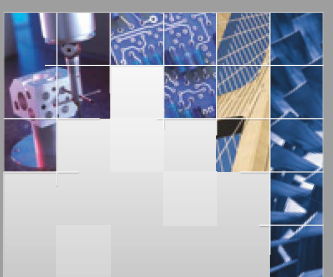

\section{Enfincering}
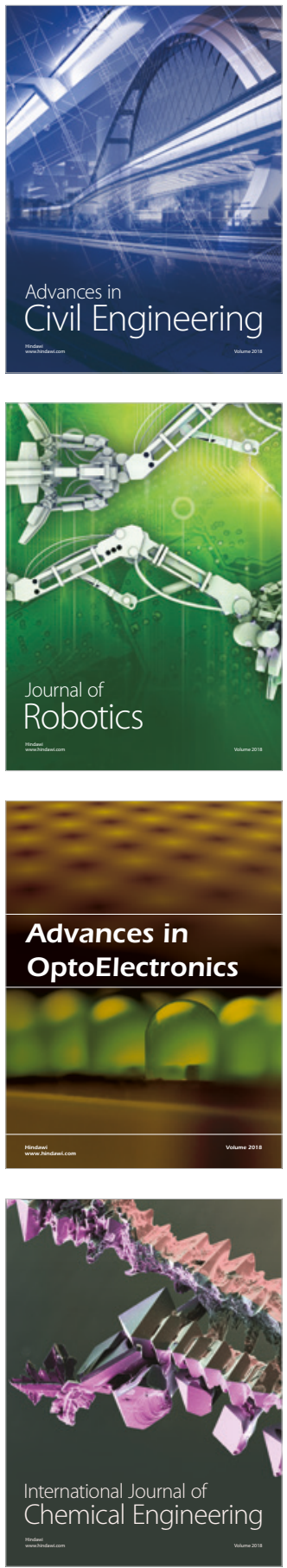

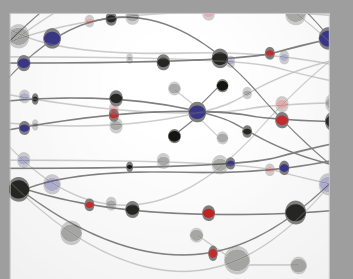

\section{Rotating \\ Machinery}

The Scientific World Journal

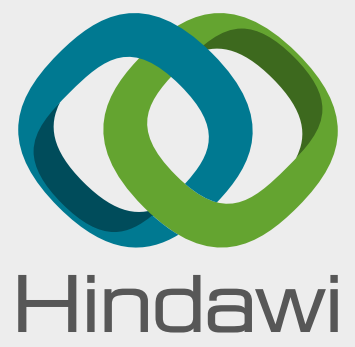

Submit your manuscripts at

www.hindawi.com
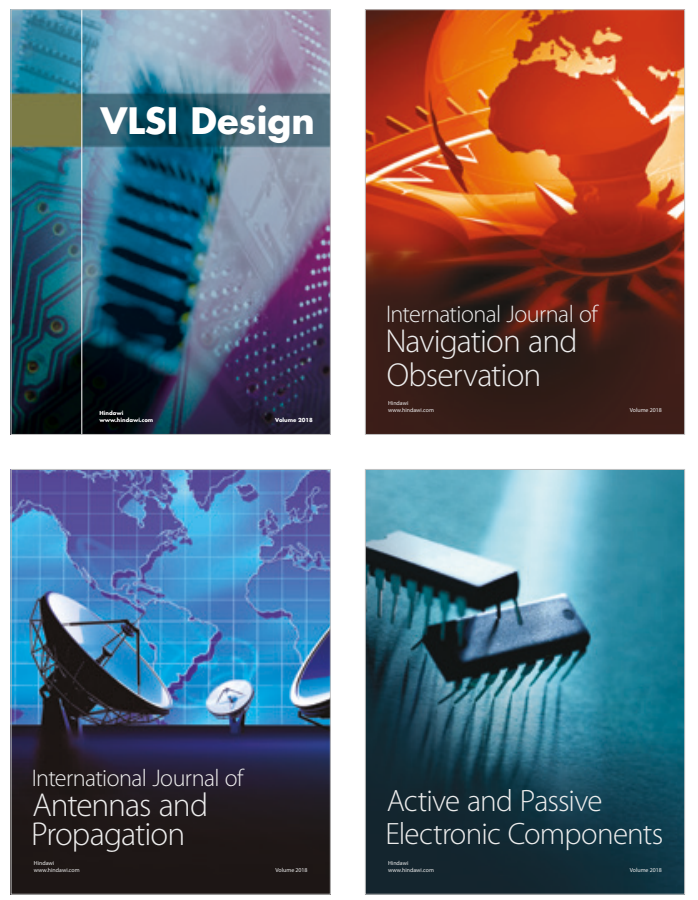
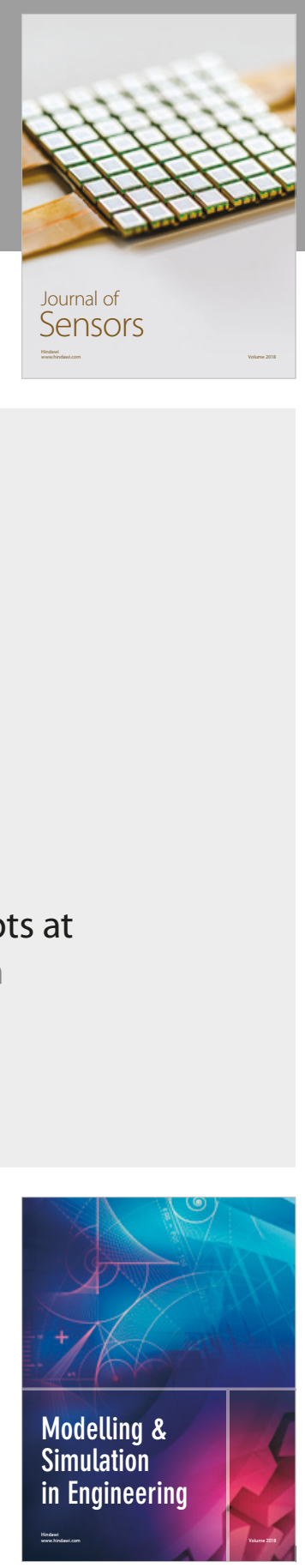

\section{Advances \\ Multimedia}
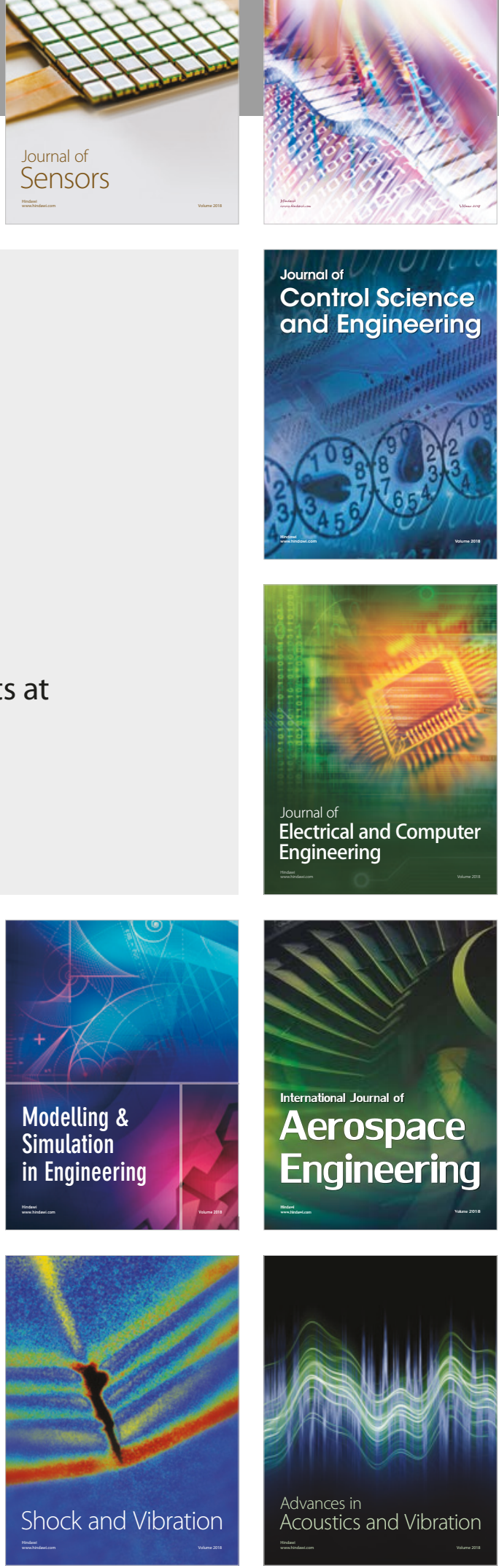